\title{
Interaction of Propionibacterium acnes with skin lipids in vitro
}

\author{
E. M. Gribbon, ${ }^{1} \uparrow$ W. J. CunlifFE ${ }^{2}$ and K. T. Holland ${ }^{1 *}$ \\ ${ }^{1}$ Skin Research Centre, Department of Microbiology, University of Leeds, Leeds LS2 9JT, UK \\ ${ }^{2}$ Department of Dermatology, Leeds General Infirmary, Leeds LSI 3EX, UK
}

(Received 23 November 1992; revised 22 February 1993; accepted 16 March 1993)

\begin{abstract}
Propionibacterium acnes is the predominant microbial resident within the pilosebaceous follicles of sebum-rich areas of human skin. This study investigated the effects of known hydrophobic components of sebum on the physiology and nutrition of this microorganism, grown anaerobically at $33^{\circ} \mathrm{C}$, under defined conditions using continuous culture techniques. The medium used was chemically defined, comprising eight amino acids, with glucose as the main carbon energy source, and the culture pH was maintained at 5.6. The range of sebum lipids assayed was based on the $\mathrm{C}_{18}$ monounsaturated fatty acid 9-cis-octadecenoic acid (oleic acid). Stock micronized solutions were aseptically pulsed into continuous cultures in the presence and absence of glucose, and nutritional effects monitored. None of the lipid substrates significantly affected $P$. acnes growth either in terms of maximum specific growth rate $\left(\mu_{\max }\right)$ or final culture biomass yield. Glycerol $\left(3 \mathrm{mg} \mathrm{ml}^{-1}\right)$ was found to be a poor carbon/energy source in comparison to glucose. Bacterial cells did, however, adhere with varying degrees, to the different lipid species, with maximum adherence occurring with the free fatty acid. This observation was confirmed by preliminary uptake experiments using $\left[{ }^{14} \mathrm{Cloleic}\right.$ acid. The interactive site for cell adherence may be the lipid-fibrillar layer associated with the cell surface of $P$. acnes, as discerned in electron microscopical studies. The findings of this investigation suggest that one function of the $P$. acnes lipase may be to aid colonization within the pilosebaceous follicle, by promoting cell adherence to components such as oleic acid.
\end{abstract}

\section{Introduction}

Propionibacterium acnes exists as one of the pre-eminent microbial inhabitants of human skin, located in the deeper recesses of the pilosebaceous follicles (McGinley et al., 1978; Leeming et al., 1984, 1985). The major sources of nutrients for these resident micro-organisms in vivo are considered to arise mainly from eccrine sweat, sebum and other structural components of the skin itself. It is unlikely that individual structural entities of human skin serve as common nutritional sources to $P$. acnes, as the integrity of the pilosebaceous follicle and skin surface would be adversely affected. The review by Noble (1981) included the characterization of eccrine sweat as a hypotonic solution comprised of $99 \%$ water by weight,

$\uparrow$ Present address. School of Biology and Biochemistry, Medical \& Biology Centre, The Queen's University of Belfast, 97 Lisburn Road, Belfast BT9 7BL, UK.

*Author for correspondence. Tel. (0532) 335647; fax (0532) 335638.

Abbreviations: DSM, defined synthetic medium; RCB, reinforced clostridial broth. with approximately equal proportions of inorganic and organic solutes. Although such constituent molecules must not be underestimated in their ability to contribute to $P$. acnes nutrition, a predominance of substrates emanates from the lipid-rich sebum.

Sebum is a holocrine secretion, comprised of a multitude of lipid species which, once secreted by the sebaceous glands, passes along the sebaceous duct into the lumen of the pilosebaceous follicle and from there to the skin surface. Nascent sebum has been found to be predominantly composed of squalene, wax esters, triglycerides and polar lipids with small amounts of diglycerides, free fatty acids and free sterols also present (Kellum, 1967; Summerly \& Woodbury, 1971). Skin surface lipid has a high percentage of free fatty acids. The reduction in triglyceride composition as sebum migrates to the skin surface is concomitant with an increase in free fatty acid composition. Marples et al. (1971) produced evidence particularly implicating the lipase of $P$. acnes in the production of free fatty acids and Ingham et al. (1981) showed that the purified lipase of $P$. acnes hydrolysed a range of triglycerides. This information tentatively suggests that the resident micro-organisms 
within the pilosebaceous follicle may gain nutritional advantage from the degradation of sebum triglycerides to their constituent free fatty acids, through the intermediary action of extracellular lipase. The components of the triglyceride fraction of nascent sebum remain to be fully characterized, although the free fatty acids derived from them range in chain length from 12 to 22 carbon atoms. Oleic acid, considered to be an important constituent of sebum, has not been ascribed a definite role in terms of $P$. acnes nutrition from the studies performed to date (Puhvel \& Reisner, 1970; Ferguson \& Cummins, 1978; Ushijima et al., 1984).

The objective of this investigation was to develop a fully defined minimal in vitro culture system in which to expose $P$. acnes to a select range of hydrophobic components derived from oleic acid, maintaining several physicochemical parameters at those values determined in vivo. The results are discussed in relation to the function of the extracellular lipase produced by this micro-organism.

\section{Methods}

Bacterial strain. A laboratory strain of Propionibacterium acnes (Type 1 of Marples \& McGinley, 1974) and designated P37 was used exclusively in these investigations. The organism had previously been isolated from an acne blackhead lesion on a patient attending the Department of Dermatology outpatients clinic, Leeds General Infirmary.

Media and growth conditions. A total of five chemostats were employed for continuous culture studies. Control modules of the LH 500 series (LH Fermentation) and Solo Biotech Series (Control Techniques) were used to regulate $\mathrm{pH}$, agitation, foaming, gas flow and gas composition. Standard 1 litre capacity culture vessels were used with working volumes ranging from $730-900 \mathrm{ml}$. The dilution rate $(D$ value) was $0.023 \mathrm{~h}^{-1}$ (corresponding doubling time, $t_{\mathrm{d}} 30.1 \mathrm{~h}$ ) with temperature and agitation rate set at $33^{\circ} \mathrm{C}$ and 250 r.p.m. respectively. All cultures were maintained at $\mathrm{pH} 5.6( \pm 0 \cdot 2)$ by the automatic addition of $2 \mathrm{M}-\mathrm{NaOH}$ or $2 \mathrm{M}-\mathrm{HCl}$. Anaerobic conditions were maintained by passing oxygen-free-nitrogen (OFN) into the culture vessel head-space at a flow rate of $100 \mathrm{ml} \mathrm{min}^{-1}$ only. Foaming was controlled by the manual addition of minimal volumes of antifoam (Polypropylene glycol 1025, BDH 29787). Batch culture experiments were done using similar fermenter vessels and operating conditions.

Experiments to determine the temperature for maximum specific growth rate were performed in Reinforced Clostridial Broth (RCB, Oxoid CM149). All other experiments used a defined synthetic medium (DSM) (K. King and K. T. Holland, unpublished) containing $24.1 \mathrm{~mm}-\mathrm{K}_{2} \mathrm{HPO}_{4} ; 11.35 \mathrm{~mm}-\left(\mathrm{NH}_{4}\right)_{2} \mathrm{SO}_{4} ; 34.22 \mathrm{~mm}-\mathrm{NaCl} ; 0.2 \mathrm{~mm}-$ $\mathrm{Mg}_{2} \mathrm{SO}_{4} ; 3.40 \times 10^{-3} \mathrm{mM}_{-} \mathrm{CaCl}_{2} ; 1.0 \times 10^{-3} \mathrm{mM}^{-\mathrm{CoCl}_{2}} ; 2.0 \times 10^{-4} \mathrm{mM}-$ $\mathrm{CuSO}_{4} ; 3.6 \times 10^{-3} \mathrm{mM}_{-} \mathrm{FeSO}_{4} ; 2.51 \times 10^{-3} \mathrm{mM}_{-} \mathrm{MnSO}_{4} ; 2.49 \times 10^{-3} \mathrm{mM}-$ $\mathrm{ZnCl}_{2} ; \quad 12.63 \mathrm{~mm}$-L-arginine; $0.416 \mathrm{mM}-\mathrm{L}$-cystine; $0.762 \mathrm{mM}$-L-isoleucine; $\quad 0.762 \mathrm{mM}$-L-leucine; $\quad 0.67 \mathrm{mM}$-L-methionine; $\quad 0.605 \mathrm{mM}$ L-phenylalanine; $\quad 3.917 \mathrm{~mm}$-L-tryptophan; $\quad 1.28 \mathrm{~mm}$-L-valine; $6.14 \times 10^{-4} \mathrm{~mm}$-biotin; $2.03 \times 10^{-2} \mathrm{~mm}$-nicotinic acid; $5.24 \times 10^{-3} \mathrm{mM}$ pantothenic acid; $6.08 \times 10^{-2} \mathrm{~mm}$-pyridoxine; $2.96 \times 10^{-2} \mathrm{~mm}$-thiamin; and D-glucose, $3 \mathrm{~g} \mathrm{l}^{-1}$, except where stated otherwise.

Determination of culture optical density. The optical density of culture samples, diluted where necessary to give values in the range
0-0.5 units, except in the experiment to determine the effect of temperature on specific growth rate (see Fig. 1): in this case, biomass was estimated from optical density measurements by using a standard curve, was measured at a wavelength of $600 \mathrm{~nm}$ using an SP6-450 uv/vis spectrophotometer (Pye Unicam).

Estimation of bacterial dry cell mass (biomass). Culture biomass (mg biomass per ml of culture) was determined directly by weight (Greenman et al., 1981).

Culture purity checks. Culture purity was routinely monitored by Gram stain and phase contrast microscopy; samples were also plated out for single colonies onto Heated Blood Agar (HBA, Oxoid CM55 and SR50) and Reinforced Clostridial Agar (RCA, Oxoid CM151), which were incubated aerobically and anaerobically under an atmosphere of $80 \% \mathrm{~N}_{2} / 10 \% \mathrm{CO}_{2} / 10 \% \mathrm{H}_{2}$ in a Microflow anaerobic cabinet (MDH) in order to detect contaminants.

Storage of culture supernatant fluids. Samples $(7 \mathrm{ml})$ of culture were centrifuged at $3000 \mathrm{~g}$ for $10 \mathrm{~min}$ using a BS 400 bench centrifuge (Denley). The culture supernatant fluid was carefully removed and stored at $-30^{\circ} \mathrm{C}$ for subsequent analyses.

Preparation of micronized stock hydrophobic solutions. Oleic acid and associated acyl glycerol derivatives were added to sterile distilled water to give the required stock concentrations. The suspensions were micronized using a $150 \mathrm{~W}$ ultrasonic disintegrator (model PG100, MSE) with a titanium microprobe (MSE, 34041), operated at a maximum amplitude of 20 microns for three bursts of $20 \mathrm{~s}$ interspersed by $20 \mathrm{~s}$ periods of cooling.

Determination of oleic acid associated with P. acnes cells. Uptake of $\left[{ }^{14} \mathrm{C}\right]$ oleic acid by $P$. acnes cells was determined using a modification of the method developed by Bojar et al. (1991). Cell suspensions (1 mg biomass $\mathrm{ml}^{-1}$ ) in phosphate buffer ( $\mathrm{pH} \mathrm{5.6)}$ were incubated at $37^{\circ} \mathrm{C}$ with gentle agitation. Sterile glucose solution $(0.2 \mathrm{M})$ was aseptically added to give a final concentration of $1 \mathrm{~mm}$. Micronized stock solutions of oleic acid were prepared in $2 \%(\mathrm{v} / \mathrm{v})$ solutions of Triton $\mathrm{X}-100$ $(\mathrm{BDH})$. The final concentrations of free fatty acid in cell suspensions were $1 \cdot 1,4.6,22 \cdot 3,11.8$ and $553.4 \mu \mathrm{M}$, and the ratios of unlabelled to labelled oleic acid within the suspensions were $5: 1,25: 1,125: 1,625: 1$ and $3125: 1$ respectively. The activity of $\left[1-{ }^{14} \mathrm{C}\right]$ oleic acid [specific activity $2030 \mathrm{MBq} \mathrm{mmol}^{-1}$ (54.9 $\left.\mathrm{mCi} \mathrm{mmol}^{-1}\right)$; Amersham CFA 243] within each experimental cell suspension was $0.01 \mu \mathrm{Ci} \mathrm{m}^{-1}$. Samples $(1 \mathrm{ml})$ were removed at different time intervals and immediately centrifuged for $30 \mathrm{~s}$ through $0.5 \mathrm{ml} 55 \%(\mathrm{v} / \mathrm{v})$ silicone oil [Dow Corning 550 silicone fluid and dinonyl phthalate (BDH)] using a Microcentaur centrifuge (MSE). The cell pellet was resuspended with vortex mixing in $1 \mathrm{ml} 1 \mathrm{M}-\mathrm{NaOH}$, prior to the addition of $0.5 \mathrm{ml} 2 \mathrm{M}$ $\mathrm{HCl}$ and $10 \mathrm{ml}$ Optiphase Safe scintillation fluid (Pharmacia/LKB). The amount of radioactivity within each sample was then determined using an LKB/Wallac 1217 Rackbeta liquid scintillation counter.

Determination of $P$. acnes cell volume. The cell volume of $P$. acnes was determined by the method of Bojar et al. (1991).

Estimation of glucose concentration. An enzymic, colorimetric glucose oxidase method (Sigma kit no. 510A) was used to determine glucose concentrations of culture supernatant fluids.

Determination of bacterial extracellular lipase activity. Extracellular lipase activity in culture supernatant fluids was assayed by measuring the release of oleic acid from triolein using a modification of the method of Ingham et al. (1981). In this procedure, a two-phase heptane/propan-2-ol/water system was used to extract long-chain free fatty acids released by enzyme activity. Subsequent titration and comparison with a range of oleic acid standard solutions allowed lipase activity to be quantified. All samples were assayed in duplicate with final enzyme activity (units) expressed as $\mu \mathrm{mol}$ oleic acid released min $^{-1}$ 


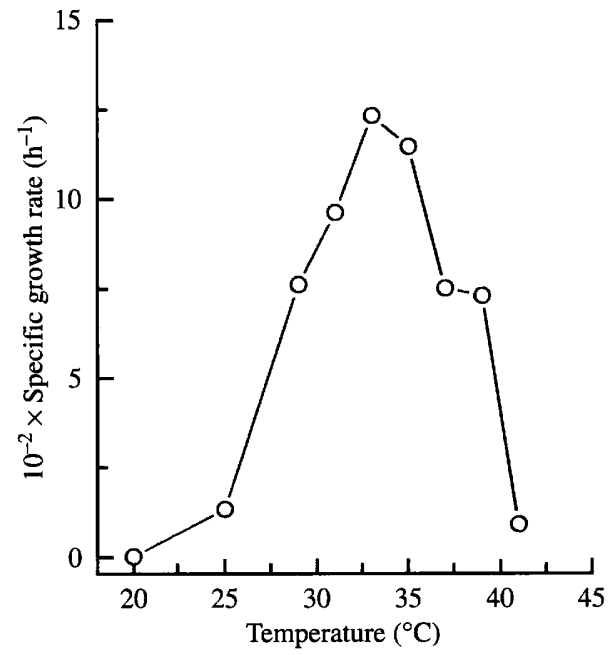

Fig. 1. Effect of temperature of incubation on the specific growth rate of $P$. acnes $\mathrm{P} 37$ in batch culture, maintained at pH 5.6 under anaerobic conditions. Specific growth rate $(\mu)$ was determined from the gradient of the regression line of a plot of $\ln$ culture biomass against time (h) in the exponential phase.

Table 1. Residual concentrations of amino acids and glucose in culture supernatant fluid from a steady-state continuous culture of $P$. acnes grown in DSM with $6 \mathrm{mg}$ glucose $\mathrm{ml}^{-1}$

Values represent the means of duplicate determinations.

\begin{tabular}{lc}
\hline Component & Concn (mM) \\
\hline D-Glucose & $-^{*}$ \\
L-Arginine & $0 \cdot 167$ \\
L-Cystine & $0 \cdot 39$ \\
L-Isoleucine & $0 \cdot 36$ \\
L-Leucine & $0 \cdot 21$ \\
L-Methionine & $0 \cdot 51$ \\
L-Phenylalanine & $0 \cdot 45$ \\
L-Tryptophan & $3 \cdot 27$ \\
L-Valine & $0 \cdot 86$ \\
\hline \hline
\end{tabular}

* Below limit of detection.

per ml culture supernatant fluid. The sensitivity of the assay was 0.01 units.

Amino acid analysis. The amino acid composition of culture supernatant fluids was determined using HPLC. All samples were derivatized using the chromophore dabcyl chloride (dimethyl amino azobenzene sulphonyl chloride) and the Amino Chrome system (CibaCorning Diagnostics). Derivatized samples were analysed using a HPLC system comprising a model 720 system controller (Waters), two column pumps (Waters M6000A), an injector (Waters U6K) and a model 440 absorbance detector (Waters) set at $436 \mathrm{~nm}$. The reverse phase Novapak $\mathrm{C}_{18}$ HPLC column (Waters) was maintained at $40{ }^{\circ} \mathrm{C}$. Column elution buffer comprised Solvent A [25 mM-sodium acetate buffer, pH 6.4 (BDH 10236) containing $4 \%$ (v/v) $\mathrm{N}, \mathrm{N}$ dimethylformamide (DMF, Sigma D-4254)] and Solvent B [acetonitrile (BDH 15285)]. The absorbance recorded at $436 \mathrm{~nm}$ was processed using a Roseate chromatography data system (Drew Scientific).

\section{Results}

Defined microbial cell growth conditions in vitro

In continuous culture, $P$. acnes was grown at $33^{\circ} \mathrm{C}$, the temperature for optimum specific growth rate in RCB (Fig. 1) and at $\mathrm{pH} 5 \cdot 6$, the optimum $\mathrm{pH}$ for stability of lipase (Eaves et al., 1979). A high specific growth rate and yield were achieved (Greenman et al., 1983).

Amino acid and glucose analyses of culture supernatant fluid from a steady-state continuous culture containing $6 \mathrm{mg}$ glucose $\mathrm{ml}^{-1}$ in DSM verified that the culture was glucose-limited (Table 1). No glucose was detected and the residual concentration of amino acid ranged from $0 \cdot 167$ to $0.86 \mathrm{mM}$.

Batch culture experiments data suggested that with glucose utilization under anaerobic conditions, arginine was transaminated to ornithine. In the supernatant fluid, $9.33 \mathrm{~mm}$-ornithinine and $0.91 \mathrm{~mm}$-citrulline were detected. In DSM, $P$. acnes produced low levels of lipase, $0.043 \pm 0.02$ units $(95 \%$ confidence level).

\section{Effects of lipids on steady-state glucose-limited continuous cultures of $P$. acnes}

The purpose of these studies was to establish if, when glucose was present as the main carbon/energy source, any of the test lipids possessed a secondary role in $P$. acnes nutrition, i.e. as a source of non-essential lipid moieties, which the micro-organism would otherwise have to synthesize. The initial concentration of each test lipid introduced into glucose-limited steady-state continuous cultures of $P$. acnes was $100 \mu \mathrm{g} \mathrm{ml}^{-1}$. In the event of no effects being recorded, the test concentration was increased to $1 \mathrm{mg} \mathrm{ml}^{-1}$.

Calculation of the theoretical concentration of residual substrate (i.e. test lipid) within the culture vessel, at a specific time interval $(t)$ after initial introduction was predicted using the formula derived by Pirt (1975),

$$
F_{\mathrm{R}}=e^{-t / t_{\mathrm{r}}}
$$

This relates the fraction of material $\left(F_{\mathrm{R}}\right)$ remaining in the culture vessel from the initial pulse to the volume of culture medium that has passed through the vessel, $t_{\mathrm{r}}$ being the period $(h)$ required to replace one culture vessel volume, and equal to the reciprocal of the culture dilution rate.

Steady-state continuous cultures of $P$. acnes were obtained in DSM with a glucose concentration of $3 \mathrm{mg} \mathrm{ml}^{-1}$. Cultures were sampled immediately after pulsing with the particular micronized hydrophobic substrate and thereafter at intervals ranging from 6 to $12 \mathrm{~h}$, depending on the nature of the effects of the various lipid species. After pulsing, steady-state conditions were re-established prior to the introduction of a subsequent 
Table 2. Effects of cutaneous lipid species on the growth and extracellular lipase activity of $P$. acnes $P 37$ in glucose-limited ( $\left.3 \mathrm{mg} \mathrm{ml}^{-1}\right)$ steady-state continuous culture $\left(D=0.023 h^{-1}\right)$

With no additions, the lipase activity was 0.043 units $\pm 0.021,95 \%$ confidence limits. ND, Not detected ( $<0.01$ units).

\begin{tabular}{|c|c|c|c|}
\hline $\begin{array}{c}\text { Test } \\
\text { substance }\end{array}$ & $\begin{array}{c}\text { Initial } \\
\text { concentration } \\
\text { in culture } \\
\mathrm{ml}^{-1}\end{array}$ & Effect on growth* & $\begin{array}{c}\text { Mean lipase } \\
\text { activity } \\
\text { (units) }\end{array}$ \\
\hline Triolein & $100 \mu \mathrm{g}$ & No effect & ND \\
\hline Triolein & $1 \mathrm{mg}$ & No effect & 0.012 \\
\hline Diolein & $100 \mu \mathrm{g}$ & $\leqslant 25$ & ND \\
\hline Diolein & $1 \mathrm{mg}$ & $25-50$ & 0.02 \\
\hline Monolein & $100 \mu \mathrm{g}$ & $25-50$ & ND \\
\hline Monolein & $1 \mathrm{mg}$ & $50-75$ & 0.026 \\
\hline Oleic acid & $15 \mu \mathrm{g}$ & $50-75$ & ND \\
\hline Oleic acid & $100 \mu \mathrm{g}$ & $75-100$ & 0.055 \\
\hline Glycerol & $1 \mathrm{mg}$ & No effect & ND \\
\hline Glycerol & $10 \mathrm{mg}$ & No effect & 0.038 \\
\hline Glucose & $1 \mathrm{mg}$ & $\begin{array}{l}\mu \text { increased from } 0.023 \text { to } \\
0.036 \mathrm{~h}^{-1} \text {. Culture } \\
\text { biomass increase from } \\
1.2 \text { to } 1.34 \mathrm{mg} \mathrm{ml}^{-1} 6 \mathrm{~h} \\
\text { post-pulsing }\end{array}$ & 0.05 \\
\hline
\end{tabular}

* Cell-to-cell aggregation and adherence to the probes and wall of the vessel expressed as a percentage of the culture biomass.

lipid moiety. A summary of the results is given in Table 2. Glycerol and triolein produced no detectable cultural changes but diolein, monoolein and, particularly, oleic acid caused increasing growth on the wall of the culture vessel. Glucose $\left(1 \mathrm{mg} \mathrm{ml}^{-1}\right)$, incorporated as the control, transiently increased $P$. acnes specific growth rate and culture biomass. Extracellular lipase activity was not increased above that of the control by addition of test substrates.

\section{Effects of lipids on continuous cultures of $P$. acnes, in the absence of glucose}

This series of experiments was devised in order to determine if any of the test lipid molecules could substitute for glucose as the main carbon/energy source in the continuous cultivation of $P$. acnes.

When glucose-limited steady-state continuous cultures of $P$. acnes in DSM, at a dilution rate of $0.023 \mathrm{~h}^{-1}$, were converted to the glucose-deficient synthetic medium, cultures effectively washed-out. The low specific growth rate in the absence of glucose, was determined from the wash-out data and culture biomass was permitted to reduce to a value of $0.35 \mathrm{mg} \mathrm{ml}^{-1}$. At this juncture, a test lipid was pulsed into the culture vessel to attain an initial concentration of $3 \mathrm{mg} \mathrm{m}^{-1}$ (i.e. equivalent to the original concentration of glucose in DSM). Substrates which promoted bacterial growth would counteract wash-out

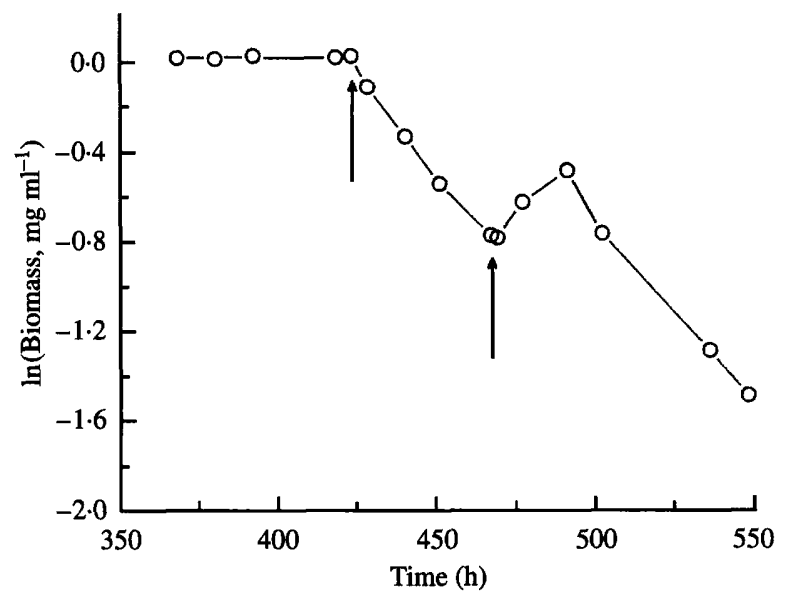

Fig. 2. Effect of a single $3 \mathrm{mg} \mathrm{ml}^{-1}$ pulse of glucose on the growth of $P$. acnes $\mathrm{P} 37$ at pH 5.6 under anaerobic conditions in a glucose-deficient medium in continuous culture, dilution rate, $0.023 \mathrm{~h}^{-1}$. The first arrow indicates the time when the inflowing medium was changed to glucosedeficient, and the second arrow indicates when glucose was added.

allowing any increase in specific growth rate and culture biomass to be determined. The culture biomass that would have been produced without wash-out was calculated from equation 1 , with $F_{\mathrm{R}}$ equal to the fraction of biomass remaining in the culture vessel. The specific growth rate was calculated from the sum of the dilution rate and the slope of the curve between the time of addition of the test substrate and the time of maximum culture biomass measured. Culture biomass was assayed immediately after introduction of the test lipid and subsequently at 6 to $12 \mathrm{~h}$ intervals.

The effects of converting a glucose-limited steady-state continuous culture of $P$. acnes in DSM to the glucosedeficient medium, and then pulsing with glucose, are shown in Fig. 2. During the effective wash-out period the specific growth rate of the micro-organism was determined as $0.008 \mathrm{~h}^{-1}$, with a corresponding doubling time $\left(t_{\mathrm{d}}\right)$ of $85 \mathrm{~h}$; the theoretical final culture biomass yield was $0.05 \mathrm{mg} \mathrm{ml}^{-1}$. Thus, since cells were still able to grow during these conditions, it was feasible to introduce alternative substrates as potential carbon/energy sources. An immediate response was evoked when glucose, the positive control, was incorporated (Fig. 2). Effective wash-out was halted and culture biomass increased for a period of $22 \mathrm{~h}$ post-pulsing with an estimated specific growth rate of $0.043 \mathrm{~h}^{-1}$ (corresponding $t_{\mathrm{d}}=16.2 \mathrm{~h}$ ). Maximum culture biomass yield (i.e. after $22 \mathrm{~h}$ ) was $0.62 \mathrm{mg} \mathrm{ml}^{-1}$, and using equation 1 the yield coefficient for glucose (i.e. the culture biomass produced from a glucose concentration of $\left.1 \mathrm{mg} \mathrm{m}^{-1}\right)$ was $0 \cdot 343$. This value lies within the expected range $(0 \cdot 35 \pm 0 \cdot 009,95 \%$ confidence levels) for the continuous cultivation of $P$. acnes in DSM, so validating the use of this assay method. Reversion of the continuous culture to effective wash-out 
Table 3. Effects of cutaneous lipid species within glucose-deficient continuous cultures of $P$. acnes $P 37$ in synthetic medium $\left(D=0.023 h^{-1}\right)$

With no additions, the lipase activity was 0.036 units $\pm 0.019,95 \%$ confidence limits. ND, Not detected ( $<0.01$ units).

\begin{tabular}{lcc}
\hline \hline $\begin{array}{c}\text { Test } \\
\text { substance } \\
\left(3 \mathrm{mg} \mathrm{m}^{-1}\right)\end{array}$ & Effect on growth* & $\begin{array}{c}\text { Maximum } \\
\text { lipase activity } \\
\text { (units) }\end{array}$ \\
\hline Triolein & 525 & 0.034 \\
Diolein & $25-50$ & 0.031 \\
Monolein & $50-75$ & $\mathrm{ND}$ \\
Oleic acid & $75-100$ & 0.022 \\
Glycerol & $\mu$ increased from 0.008 to $0.014 \mathrm{~h}^{-1}$. & 0.016 \\
& Culture biomass increased from \\
Glucose & 0.05 to $0.48 \mathrm{mg} \mathrm{m}^{-1}$ & \\
& $\mu$ increased from 0.008 to $0.043 \mathrm{~h}^{-1}$. \\
& Culture biomass increased from & 0.035 \\
& 0.05 to $1.03 \mathrm{mg} \mathrm{m}^{-1}$ \\
\hline
\end{tabular}

* Cell-to-cell aggregation and adherence to the probes and wall of the vessel expressed as a percentage of the culture biomass.

after $22 \mathrm{~h}$ (Fig. 2) was concomitant with the emergence of glucose-deplete conditions. A synopsis of the results for the various test substrates is presented in Table 3. None of the lipid species assayed appeared to be utilized by $P$. acnes as carbon/energy sources, nor did they affect production of extracellular lipase by this micro-organism. Cell adherence was, however, an overwhelming effect, increasing in magnitude along the lipid range from triolein to oleic acid; this prevented an acumen into the role of the hydrophobic substrates solely as sources of carbon and/or energy compared to glucose. Glycerol was a relatively poor carbon/energy source and did not stimulate bacterial lipase activity.

\section{Uptake of oleic acid by cells of P. acnes}

Oleic acid is the common constituent of the lipid range utilized in this investigation. Elucidation of the nature of its transport into cells may establish if extracellular lipase activity is associated with lipid uptake. Specific moieties, exceeding a size limitation imposed by the lipid transport system, may have to be degraded to their constituent molecules via lipase activity, prior to translocation.

The silicone oil method was shown to be effective in separating cell-associated oleic acid from that remaining in suspension, with total radioactivity accounted for in each series of experiments. Oleic acid uptake by viable $P$. acnes cells was concentration-dependent and exhibited saturation-type kinetics (Fig. 3). However, a similar relationship between initial reaction velocity and oleic acid concentration was determined for heat-killed $P$. acnes cells. The apparent concentration of oleic acid within living and heat-killed cells after translocation was 40 to 50 times greater than the external substrate

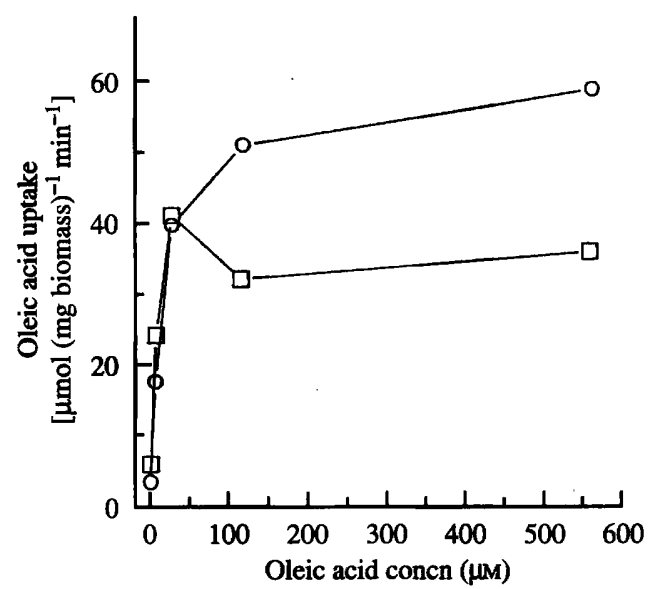

Fig. 3. Effect of oleic acid concentration on the velocity of its uptake by viable $(O)$ and heat-killed $(\square)$ cells of $P$. acnes $\mathrm{P} 37$ at pH 5.6 and $33^{\circ} \mathrm{C}$.

concentration. This situation prevailed for both cell types at each oleic acid concentration assayed, suggesting that the cell/substrate interaction is one of adherence.

\section{Discussion}

Preliminary nutritional and physiological studies established the optimum conditions in vitro for the anaerobic propagation of $P$. acnes in a fully defined and controllable aqueous environment. The conditions satisfied the essential prerequisites for determining the effects of selected skin lipids on microbial growth; these included the absence of all lipid moieties, known or undefined, from the culture medium, and physicochemical parameters (temperature and $\mathrm{pH}$ ) resembling, where possible, those of the natural ecological niche of the micro-organism. Furthermore, by culturing $P$. acnes in continuous culture at relatively low dilution rates, the system is analogous to the situation in vivo, where the continual flow of sebum through the pilosebaceous follicle establishes crude continuous culture conditions (Cove et al., 1983). One outstanding feature of the follicular environment, however is the low water content (Noble, 1981), a parameter which is not easily replicated in vitro when considering bacterial growth. Maximum specific growth rate and culture biomass were obtained in the synthetic medium containing glucose. However, there are no reports of glucose availability in the follicle of human skin.

The anaerobic growth and lipase activity of $P$. acnes in synthetic medium, with glucose present as the main carbon/energy source, was not stimulated by addition of any of the $C_{18}$ monounsaturated-fatty-acid lipid range. Also, the hydrophobic compounds had no apparent growth-promoting or growth-inhibiting effects in the absence of glucose. However, growth stimulation could 
not be accurately quantified, as a consequence of the overwhelming effects of the lipids tested on cell adherence. Glycerol was ascertained to be a poor carbon/ energy source for $P$. acnes, with associated low lipase production. Lipase activity in this particular strain was suppressed when either glucose or glycerol were present in the culture medium (Holland et al., 1979). This observation was confirmed by Greenman et al. (1981) at high glucose concentrations $(0.5 \%, \mathrm{w} / \mathrm{v})$. These findings do not appear to justify the proposition (Puhvel \& Reisner, 1970; Rebello \& Hawk, 1978) that the role of the extracellular lipase is to provide $P$. acnes with a supply of glycerol, as a carbon/energy source.

The initial work of Puhvel \& Reisner (1970), propounding oleic acid as stimulatory to $P$. acnes growth, was corroborated by Ferguson \& Cummins (1978). The growth promoting effect decreased with increasing unsaturation of fatty acid, and the $\mathrm{C}_{18}$ di- and triunsaturated species (linoleic and linolenic acids) were inhibitory for P. acnes (Puhvel \& Reisner, 1970; Ko et al., 1978). Oleic acid has been postulated to substitute for biotin in $P$. acnes nutrition (Puhvel \& Reisner, 1970; Ferguson \& Cummins, 1978), although the mechanism by which this is achieved remains a matter of contention.

The outstanding relationship between $P$. acnes and the hydrophobic species assayed in this investigation was cell adherence, increasing in magnitude along the series from triolein to oleic acid, with no evident alteration in extracellular lipase activity. Maximum cell-to-cell aggregation and adherence resulted when $3 \mathrm{mg}$ oleic acid $\mathrm{ml}^{-1}$ was added to the culture. Studies carried out in the author's laboratory have shown that agitation of $P$. acnes cultures results in lower yields. It is possible that aggregation of cells results in higher yields because of more efficient nutrition of groups of cells compared to physically separated cells. Consequently, the reports noted above, indicating that lipids promote growth, may be explained by their aggregation effects on cells rather than as direct nutrients.

An increase in cell adherence, but not culture biomass, also occurred when Tween 80 , initial concentration $0 \cdot 1$ and $1 \%(\mathrm{v} / \mathrm{v})$ was pulsed into glucose-limited steadystate continuous cultures of $P$. acnes in DSM. Therefore, the findings of Ferguson \& Cummins (1978) that Tween 80 acted as a source of oleic acid and stimulated $P$. acnes growth in vitro could not be confirmed. It is of interest, however, that Tween 80 was able to initiate cell adherence, although to a lesser degree than free oleic acid. This could be attributed to the lower relative concentration of the free fatty acid within the Tween complex. Stromberg \& Karlsson (1990) showed that $P$. granulosum, which is closely related to $P$. acnes but less prevalent on human skin, binds to lactyl-ceramides (glycosphingolipid). The lactose moiety of the glyco- phospholipid was extremely important, whilst the ceramide moiety modulated the binding. For $P$. granulosum, lipids might appear to be less important in adhesion than for $P$. acnes and, if this is correct, then in the sebaceous follicles and on the skin there would be no competition between the species for sites to colonize. McGinley et al. (1978) have shown that $P$. acnes and $P$. granulosum can be isolated from the same sites and $P$. avidum has a more restricted habitat. It would be interesting to determine whether $P$. avidum adheres to glycosphingolipids and oleic acid.

The levels of $P$. acnes extracellular lipase activity recorded in this study are low. This meagre lipase production may pertain in vivo (Cove et al., 1983), since the enzyme is stable (Ingham et al., 1981) within the cutaneous environment and the low water content would increase enzyme concentration, thereby increasing the rate of triglyceride hydrolysis. In addition, the lipase produced by $P$. acnes is non-specific (Ingham et al., 1981), catalysing total hydrolysis of triacylglycerols to free fatty acids and glycerol (Finnerty, 1989).

The extracellular lipase of $P$. acnes is proposed here as a possible colonization factor in vivo. Low enzyme activity, immediately surrounding the bacterial cell may ensure a concentration of oleic or possibly other free fatty acids, suitable for provoking cell-to-cell adherence and subsequent anchoring of the bacterial cells within the continuously changing milieu of the pilosebaceous follicle. It is possible that aggregation of cells promotes cooperative cell nutrition and has effects on the local micro-environment which are more conducive to $P$. acnes colonization.

The authors wish to thank the Leeds Foundation for Dermatological Research for their financial support.

\section{References}

Bojar, R. A., Holland, K. T. \& CunlifFe, W. J. (1991). The in vitro antimicrobial effects of azelaic acid upon Propionibacterium acnes strain P37. Journal of Antimicrobial Chemotherapy 28, 843-853.

Cove, J. H., Holland, K. T. \& CunlifFe, W. J. (1983). Effects of oxygen concentration on biomass production, maximum specific growth rate and extracellular enzyme production by three species of cutaneous propionibacteria grown in continuous culture. Journal of General Microbiology 129, 3327-3334.

Eaves, G., Greenman, J. \& Holland, K. T. (1979). Decay rates of extracellular enzymes produced by bacteria-correction of production rates in chemostat cultures. FEMS Microbiology Letters 6 , 333-336.

Ferguson, D. A. \& Cummings, C. S. (1978). Nutritonal requirements of anaerobic coryneforms. Journal of Bacteriology 135, 858-867.

FINNERTY, W. R. (1989). Microbial lipid metabolism. In Microbial Lipids, vol. 2, pp. 525-566. Edited by C. Ratledge \& S. G. Wilkinson. London. Academic Press.

Greenman, J., Holland, K. T. \& CunlifFe, W. J. (1981). Effects of glucose concentration on biomass, maximum specific growth rate and extracellular enzyme production by three species of cutaneous propionibacteria grown in continuous culture. Journal of General Microbiology 127, 371-376. 
Greenman, J., Holland, K. T. \& Cunliffe, W. J. (1983). Effects of $\mathrm{pH}$ on biomass, maximum specific growth rate and extracellular enzyme production by three specimens of cutaneous propionibacteria grown in continuous culture. Journal of General Microbiology 129, 1301-1307.

Holland, K. T., Greenman, J. \& Cunliffe, W. J. (1979). Growth of cutaneous propionibacteria on synthetic medium; growth yields and exoenzyme production. Journal of Applied Bacteriology 47, 383-394.

Ingham, E., Holland, K. T., Gowland, G. \& Cunliffe, W. J. (1981). Partial purification and characterization of lipase (EC 3.1.1.3) from Propionibacterium acnes. Journal of General Microbiology 124, 393-401.

Kellum, R. E. (1967). Human sebaceous gland lipids. Archives of Dermatology 95, 218-220.

Ko, H. L., Heczko, P. B. \& Pulverer, G. (1978). Differential susceptibility of Propionibacterium acnes, $P$. granulosum and $P$. avidum to free fatty acids. Journal of Investigative Dermatology $\mathbf{7 1}$, 363-365.

Leeming, J. P., Holland, K. T. \& Cunliffe, W. J. (1984). The microbial ecology of pilosebaceous units isolated from human skin. Journal of General Microbiology 130, 803-807.

Leeming, J. P., Holland, K. T. \& Cunliffe, W. J. (1985). The pathological and ecological significance of microorganisms colonising acne vulgaris comedones. Journal of Medical Microbiology 20, 11-16.

MARPLES, R. R. \& MCGinley, K. J. (1974). Corynebacterium acnes and other anaerobic diphtheroids from human skin. Journal of Medical Microbiology 7, 349-357.
Marples, R. R., Downing, D. T. \& Kligman, A. M. (1971). Control of free fatty acids in human surface lipids by Corynebacterium acnes. Journal of Investigative Dermatology 56, 127-131.

McGinley, K. J., Webster, G. F. \& Leyden, J. J. (1978). Regional variations of cutaneous propionibacteria. Applied and Environmental Microbiology 35, 62-66.

NoBLE, W. C. (1981). Nutrient factors. In Microbiology of Human Skin, pp. 26-65. Edited by A. Rook. London: Lloyd-Luke Ltd.

PIRT, S. J. (1975). Principles of Microbe and Cell cultivation. Oxford: Blackwell Scientific Publications.

Puhvel, S. M. \& Reisner, R. M. (1970). Effect of fatty acids on the growth of Corynebacterium acnes in vitro. Journal of Investigative Dermatology 54, 48-52.

ReBello, T. \& HAWK, J. L. M. (1978). Skin surface glycerol levels in acne vulgaris. Journal of Investigative Dermatology 70, 352-354.

Stromberg, N. \& Karlsson, K. A. (1990). Characterization of the binding of Propionibacterium granulosum to glycosphingolipids adsorbed on surfaces. Journal of Biological Chemistry 265, 11244-11250.

SUmmerly, R. \& Woodbury, S. (1971). The in vitro incorporation of $\left[{ }^{14} \mathrm{C}\right]$ acetate into the isolated sebaceous glands and appendage-freed epidermis of human skin. A technique for the study of lipid synthesis in the isolated sebaceous gland. British Journal of Dermatology 85, $424-431$

UshiJima, T., Takahashi, M. \& Ozaki, Y. (1984). Acetic, propionic and oleic acid as the possible factors influencing the predominant residence of some species of Propionibacterium and coagulasenegative Staphylococcus on normal skin. Canadian Journal of Microbiology 30, 647-652. 